\title{
Incorporation of Actinide Elements into Iron-Zirconium Intermetallic Phases in Metallic Waste Forms for High-Level Nuclear Waste
}

\author{
D.E. Janney*
}

*Argonne National Laboratory-West, Idaho Falls, ID 83403

Argonne National Laboratory is developing and demonstrating a metallic waste form to incorporate actinide elements (U, Np, Pu) and metal fission products (including $\mathrm{Nb}, \mathrm{Tc}, \mathrm{Ru}, \mathrm{Rh}, \mathrm{Pd}$, and $\mathrm{Ag}$ ) separated during electrometallurgical refining of spent nuclear fuel assemblies [1-3]. The baseline composition of the waste form is stainless steel alloyed with $15 \mathrm{wt} \% \mathrm{Zr}$ (SS-15Zr). Dissolution experiments show that, although release levels for all constituents of the metallic waste form are comparable to or lower than those for borosilicate glasses, those for $U$ are significantly higher than those for other any other element (including Fe) [3]. Detailed microstructural characterization of the actinide-bearing phases is necessary to understand this phenomenon.

Scanning electron microscope (SEM) images of SS-15Zr simulated waste forms consistently show eutectic intergrowths of Fe-Zr intermetallic phases with steels and demonstrate that actinide elements are almost entirely confined to the intermetallics [1-3]. Images of samples containing actinides show bright and dark patches separated by gradual transitions within the intermetallic areas; energy- and wavelength-dispersive X-ray spectrometry (EDS and WDS) indicate that these areas correspond to regions with high (up to 20 at\% in a sample with $11 \mathrm{wt} \% \mathrm{U}$ ) and low (1-2 at\%) concentrations of actinides respectively [2]. Neutron-diffraction studies indicate the presence of phases with structures similar to $\mathrm{C} 15 \mathrm{Fe}_{2} \mathrm{Zr}$ (cubic, $\mathrm{MgCu}_{2}$-type), C36 $\mathrm{Fe}_{2} \mathrm{Zr}$ (dihexagonal, $\mathrm{MgNi}_{2}$-type), and $\mathrm{Fe}_{23} \mathrm{Zr}_{6}$ in SS$15 Z$ r. Previous research using electron diffraction from a sample of SS-15Zr with $5 \mathrm{wt} \% \mathrm{U}$ and 2 wt $\%$ Tc indicates the presence of two additional intermetallic phases: one similar to $\mathrm{C}_{14} \mathrm{Fe}_{2} \mathrm{Zr}$ (hexagonal, $\mathrm{MgZn}_{2}$-type) and one with six-layer hexagonal stacking. The electron diffraction data also suggest that the actinide-concentration gradients in the SEM images may be consequences of a quasi-continuous series of polytypes with $\mathrm{Fe}_{2} \mathrm{Zr}$-type structures, each of which has different proportions of $\mathrm{Fe}, \mathrm{Cr}$, and $\mathrm{Ni}$ and a different preference for actinide elements [2].

This presentation reports current results from an on-going detailed microstructural characterization of actinide-bearing phases in SS-15Zr metal waste forms using transmission electron microscopy (TEM), EDS, and electron diffraction. These results are from two samples: one with 5 wt\% U (SS$15 \mathrm{Zr}-5 \mathrm{U})$ and one with $2 \mathrm{wt} \% \mathrm{~Np}(\mathrm{SS}-15 \mathrm{Zr}-2 \mathrm{~Np})$. All of the current results are from areas in which actinide concentrations are estimated to be a few atomic $\%$.

Samples were prepared for transmission electron microscopy by using a low-speed saw to cut pieces $\sim 1 \mathrm{~mm}$ thick, grinding with progressively finer abrasives to a final thickness of $\sim 20 \mathrm{~nm}$ with a 1200grit polish on both sides, gluing fragments to copper TEM grids, and ion milling to perforation. Microscopy was carried out using a JEOL 2010 TEM operating at $200 \mathrm{kV}$ and an Oxford Link energy-dispersive X-ray detector.

Tilting experiments were carried out to collect a number of zone-axis diffraction patterns from several crystals in each sample. Data from twelve crystallographically distinct zone axes were collected in SS-15Zr-2Np, and from about seventeen in SS-15Zr-5U. 
All of the diffraction patterns from intermetallic crystals in SS-15Zr-2Np could be indexed as belonging to the $\mathrm{C} 15 \mathrm{Fe}_{2} \mathrm{Zr}$ structure. With one exception, which had numerous twins, these crystals had very few dislocations and no planar defects visible in bright-field images. EDS data show variations in the $\mathrm{Fe} / \mathrm{Ni}$ ratio with essentially constant concentrations of $\mathrm{Cr}$ and $\mathrm{Zr}$ (Fig. 1a).

In contrast, bright-field images of low-actinide intermetallics in SS-15Zr-5U show abundant closely spaced planar defects with at least three orientations. Diffraction patterns from this sample do not represent the structure observed in SS-15Zr-2Np; however, it has not been possible to index all of the diffraction patterns from this sample using d-spacings from any single previously reported $\mathrm{Fe}_{2} \mathrm{Zr}$ intermetallic structure or from $\mathrm{Fe}_{23} \mathrm{Zr}_{6}$. The EDS data show a consistently smaller fraction of Ni than do SS-15Zr-2Np analyses, with relatively little variation in the fractions of Fe and Zr (Fig. 1b).

Research involving the host phases of actinides in simulated metallic waste forms based on SS-15Zr continues. Topics for future work include identification of the crystal structure(s) and planar defects in SS-15Zr-5U, characterization of phases with higher concentrations of actinides, and analysis of samples containing $\mathrm{Pu}[4]$.

\section{References}

[1] S.M. McDeavitt et al., J. Nucl. Materials 257 (1998) 21-34.

[2] D.D. Keiser Jr. et al., J. Nucl. Materials 279 (2000) 234-244.

[3] S.G. Johnson et al., MRS Symposium, "Scientific Basis for Waste Management" (2001)

[4] Argonne National Laboratory is operated for the US Department of Energy by the University of Chicago. This work was supported by the US Department of Energy, Office of Nuclear Energy, Science, and Technology, under contract W-31-109-ENG-38. I thank Tom O'Holleran, Tom DiSanto, Dennis Keiser, Steve Johnson, and Mark Surchik for advice and assistance.
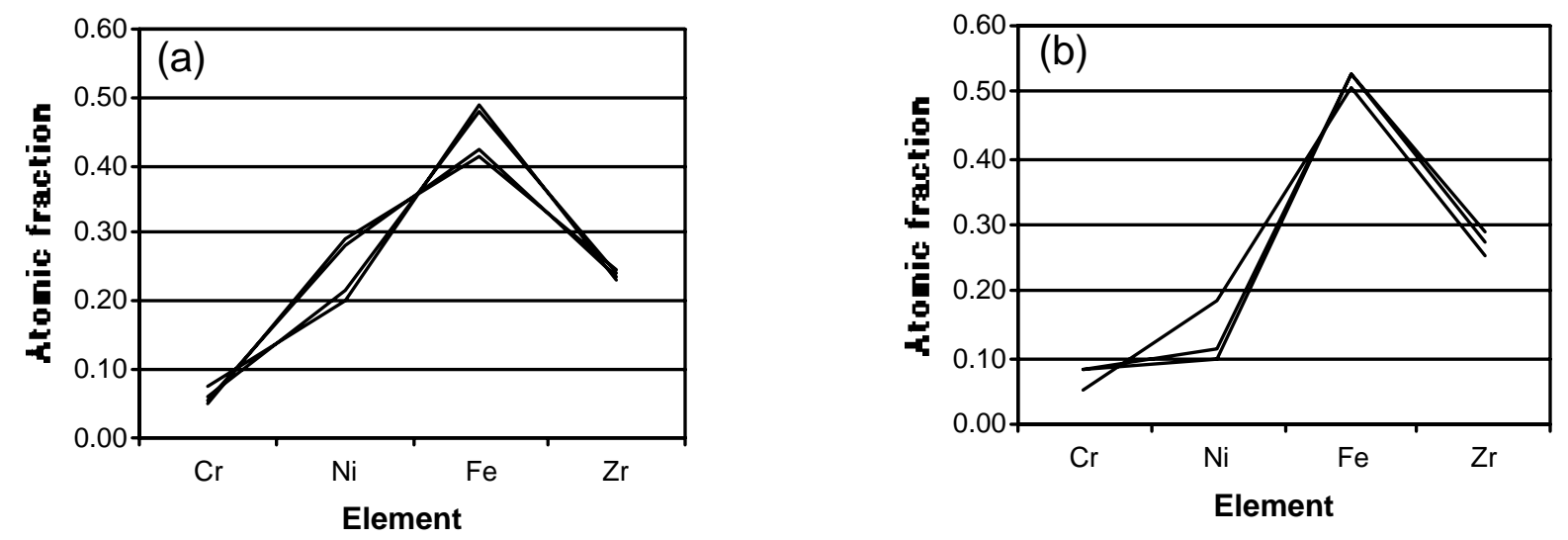

Fig. 1: Selected EDS analyses illustrating the range of compositional variability in Fe-Zr intermetallics in (a) SS-15Zr-2Np and (b) SS-15Zr-5U, normalized so that atomic fractions of $\mathrm{Cr}$ $+\mathrm{Ni}+\mathrm{Fe}+\mathrm{Zr}=1$ for each analysis. Lines connect measurements from one EDS spectrum. Data in (a) are from a single crystal. 